\title{
Oszillierendes Bohren
}

Dankward Höntzsch

Oszillierendes Bohren wird häufig vergessen.

Ich bin immer wieder erstaunt, wir wenig das gewusst oder nicht benutzt wird.

Moderne Maschinen haben diesen Modus.

Oszillierendes Bohren hat 2 Vorteile: Wenn auf der „Gegenseite“ gefährdetes Gewebe (Nerven, Gefäße) liegen, piekt der Bohrer nur etwaiges gefährdetes Gewebe und wickelt es nicht auf. Das gleiche ist der Fall, wenn einmal eine Bohrung durch Weichteile zum Knochen geht, wo keine ausreichend lange Bohrbüchse zur Verfügung steht. Auch hier bewahrt das oszillierende Bohren vor dem Aufwickeln.

Bewährt hat sich dieses Verfahren auch bei geschlossener oder semioffener Insertion von Kirschner-Drähten, z.B. bei kindlichen suprakondylären Frakturen. So wird die Schädigung z. B. des Nervus ulnaris, wenn er nicht dargestellt worden ist, wesentlich reduziert.

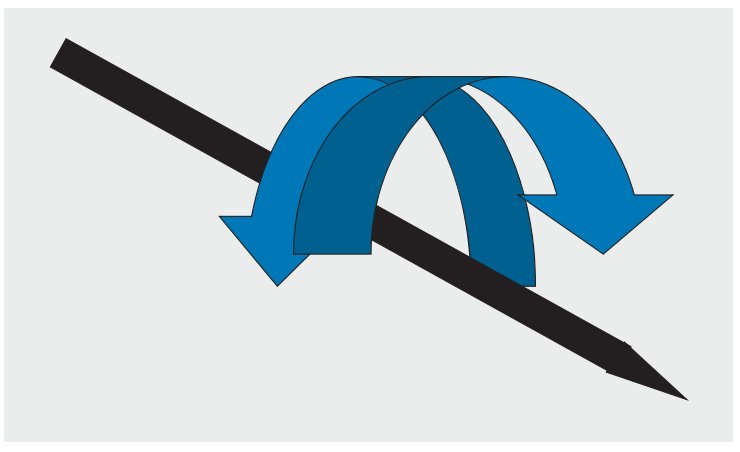

Sehr schön kann man den Effekt des oszillierenden Bohrens mit einer ausgelegten Kompresse zeigen. Beim normalen rotierenden Bohren wird diese ganz rasch aufgewickelt. Beim oszillierenden Bohren kann man mühelos durch eine Kompresse durchbohren. Probieren Sie es aus!

Korrespondenzadresse

Prof. Dr. Dankward Höntzsch

Tübingen

hoentzsch@t-online.de 